\title{
AMBIENTE VIRTUAL PARA ENSINO E APRENDIZAGEM DE FISIOLOGIA ANIMAL
}

\author{
Eliane Pozzebon \\ Universidade Federal de Santa Catarina \\ eliane.pozzebon@ufsc.br \\ Maria Eduarda Torres da Silveira \\ Universidade Federal de Santa Catarina \\ m.eduardats@gmail.com \\ Samuel Ghisleri Minatto \\ Universidade Federal de Santa Catarina \\ samuelminatto@hotmail.com
}

\section{Resumo}

O uso de Ambientes Virtuais com animações, vídeos e hipertextos despertam mais a curiosidade dos alunos e prendem sua atenção quando comparado ao método tradicional, tornando assim replicável esse tipo de ensino. O presente projeto teve como objetivo o desenvolvimento de uma ferramenta para auxílio no ensino-aprendizagem de conteúdos do aparelho digestório em escolas. Para atingir o objetivo foi realizado um estudo referente ao aparelho digestório e às tecnologias que poderiam ser utilizadas no desenvolvimento do Ambiente Virtual. A partir disto foi implementado o protótipo do AVIFA. Efetuaram-se então os testes e correções detectados nas experimentações realizadas na escola. Com o AVIFA concluído fez-se a validação com 24 alunos de uma escola. Como resultado foi obtido $84 \%$ de aprovação dos alunos de que as aulas tornariam mais interessantes com o AVIFA. Os outros $16 \%$ se dividiram: metade achavam que seria interessante, e a outra metade que preferiria o método tradicional.

Palavras-chave: Ambiente Virtual Interativo. Fisiologia Animal. Informática na Escola

\section{VIRTUAL ENVIRONMENT TO TEACHING AND STUDYING OF THE ANIMAL PHYSIOLOGY}

\section{Abstract}

The use of Virtual Environments with animations, videos and more hypertext hold students attention with more efficiency when compared to traditional methods, making this type of teaching replicable. This project aimed to develop of the tool to support the teaching and studying process of the digestive system in schools. To achieve this goal, a study concerning the digestive system was developed, as well as the technologies that could be used to create the virtual environment. From that moment on, a prototype of the AVIFA. Tests were carried out and then corrections were detected in the experiments conducted in school. With AVIFA completed, the validation was done with 24 students of the school. The result was $84 \%$ of approval of the students. The other $16 \%$ are split: half of them think that the method is interesting, and the other half prefer the traditional method.

Keywords: Interactive Virtual Environment. Animal Physiology. Informatics in school

\section{ENTORNO VIRTUAL DE ENSEÑANZA Y APRENDIZAJE DE LA FISIOLOGÍA ANIMAL}

\section{Resumen}

Los ambientes virtuales con animaciones, vídeos e hipertextos despiertan más la curiosidad de los estudiantes y mantienen más la atención si en comparación con el método tradicional, por eso puede ser aplicable este tipo de enseñaza. Este proyecto tiene como objetivo desarrollar una herramienta para ayudar en los contenidos de enseñanza-aprendizaje del aparato digestivo en las escuelas. Para lograr el objetivo se realizó un estudio sobre el aparato digestivo y las tecnologías que podrían ser utilizados en el desarrollo del ambiente virtual. Para alcanzar el éxito fue implementado el prototipo 
AVIFA. Efectúaranse los tests y correcciones en los experimentos llevados a cabo en la escuela. Con AVIFA concluido la validación fue realizada con 24 estudiantes de una escuela. El resultado fue la aprobación del $84 \%$ de los estudiantes pues las lecciones se hacen más interesantes con AVIFA. El otro 16\% se divide: la mitad les parecía interesante, y a la otra mitad prefiere el método tradicional.

Palabras clave: Ambiente virtual interactivo . Fisiología Animal. Computación en la escuela 


\section{INTRODUÇÃO}

Para auxiliar no ensino-aprendizagem são utilizados ambientes denominados Ambientes Virtuais de Aprendizagem - AVAs, também conhecidos na literatura por Learning Management Systems - LMS. Estes ambientes suportam o processo de comunicação entre alunos, professores, materiais didáticos e a comunidade, fazendo com que todos participem de modo interativo, tanto no meio acadêmico como no meio corporativo (KEMCZINSKI, 2005).

Os AVAs facilitam o processo de visualização e de interação com os conteúdos propostos, possibilitando o desenvolvimento de uma forma de estudo mais interessante e atrativa por meio da interação com diferentes tipos de mídias, como imagens, vídeos, etc. Estas ferramentas possibilitam o crescimento e a construção de conhecimento por meio da interação do aluno com o sistema em questão, gerando por muitas vezes uma grande autonomia por parte deste em relação aos percursos que envolvem seus estudos.

A aprendizagem tem um papel fundamental para o desenvolvimento do saber, do conhecimento, portanto o ambiente virtual compreende a apresentação da fisiologia animal aos estudantes de uma forma prática e interativa, demonstrando eficácia por meio das diferentes mídias que apresenta em seu ambiente, prezando pela qualidade no processo de ensino.

Com a utilização de tecnologias em sala de aula, o professor deixa de ser o detentor do conhecimento e passa a ser um mediador entre o aluno e as tecnologias. Além disso, como afirma Roehrs; Muller e Arruda (2014), “as Tecnologias da Informação e Comunicação (TIC's) em Educação são recursos/ferramentas imprescindíveis na vida do professor, desde que sejam exploradas de forma criativa e interativa", elas têm o poder de tornar o aluno construtor de seu próprio conhecimento.

Este artigo descreve as experiências resultantes de um projeto cujo objetivo principal foi o desenvolvimento do ambiente virtual interativo para ensino e aprendizagem de fisiologia animal. $\mathrm{O}$ ambiente virtual proposto possui, ainda, um grande compromisso para com os direitos e a preservação dos animais, se apresentando como uma ferramenta de substituição às diversas experiências práticas que são, frequentemente, realizadas com os mesmos.

As justificativas de escolha do domínio são: (a) facilitar a aprendizagem e torná-la mais interessante ao aluno e ao professor; (b) minimizar o uso de animais em aulas expositivas; (c) integrar o professor a nova realidade tecnológica e apresentar o curso de Tecnologias de Informação e Comunicação; e (d) instigar o interesse dos alunos para ingressarem numa universidade pública de qualidade e num curso com alta defasagem de profissionais qualificados. 


\section{METODOLOGIA E MÉTODOS}

O desenvolvimento do protótipo do ambiente interativo virtual cujo objetivo foi simular com animações hipermídia o conteúdo das aulas teóricas, para facilitar a sua fixação e aprendizado, e das aulas práticas que se restringem a estudos laboratoriais foi construído por dois bolsistas e a professora do curso de Tecnologia da Informação e Comunicação da Universidade Federal de Santa Catarina com a colaboração de uma professora e alunos do curso de Medicina Veterinária da Universidade do Vale do São Francisco.

O projeto foi dividido em duas etapas. Na primeira etapa foi realizado o levantamento bibliográfico e a análise de sistemas para a elaboração de um modelo preliminar do ambiente de aprendizagem. $\mathrm{Na}$ segunda etapa foi realizada a escolha das ferramentas computacionais, a implementação, os testes e validações com estudantes da escola pública.

Para a criação das animações foi utilizado a hipermídia como alternativa para a simulação. O termo hipermídia pode ser descrito como resultante da junção de dois tipos de dados: hipertexto (conjunto de textos interconectados com elos para navegação) e multimídia (conjunto de vídeos, sons, imagens e animações), como apresentado na figura 1, resultando assim um conjunto de mídias para a concepção de ambiente interativo.

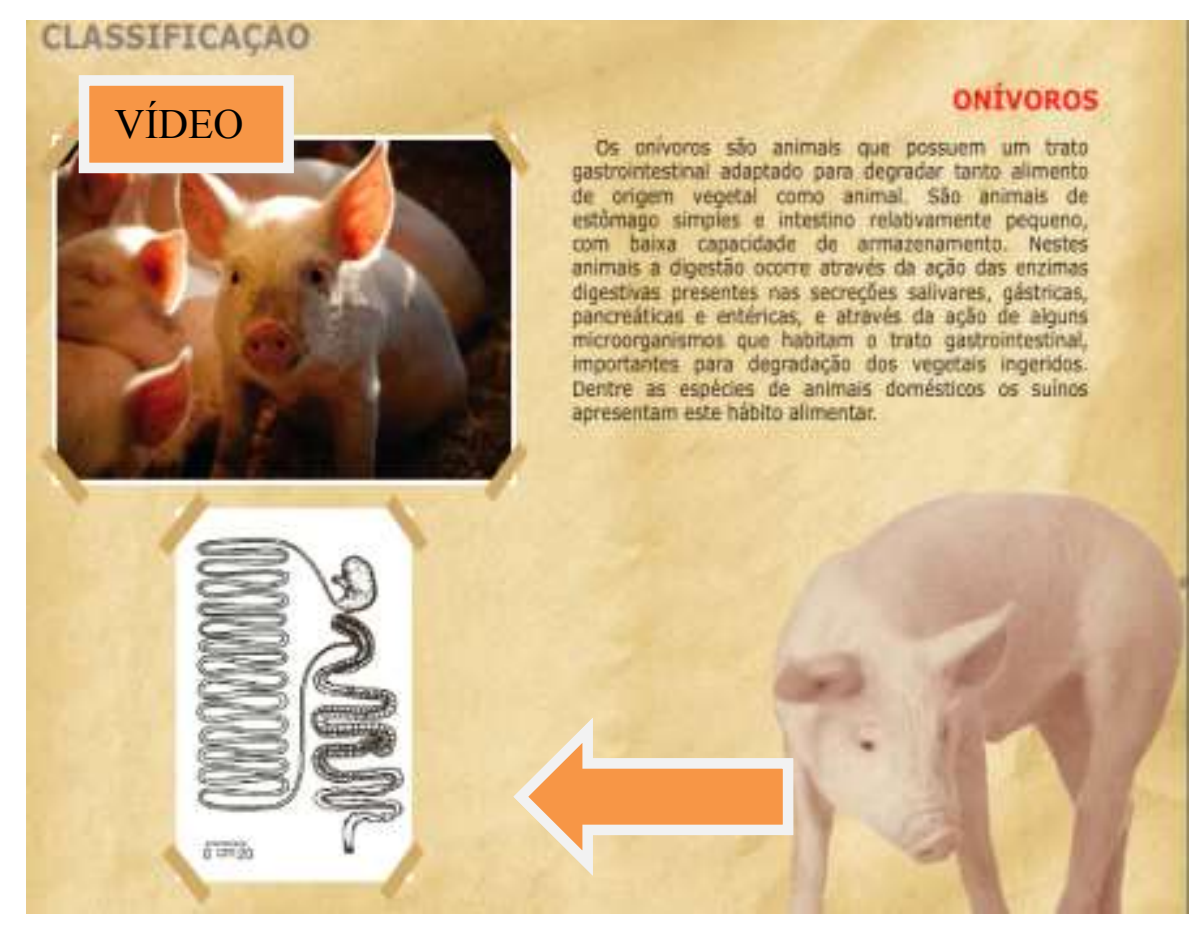

Figura 1 - Ambiente Virtual para facilitar o aprendizado e compreensão Fonte: Elaborado pelos autores, 2015. 
A validação da ferramenta de auxílio no ensino de conteúdo do aparelho digestório foi realizada na rede pública, onde grupos de estudantes da Escola pública Maria Garcia Pessi interagiram com o ambiente virtual e responderam um questionário de avaliação (Figura 2). A escolha da escola foi pela proximidade geográfica da Universidade Federal de Santa Catarina Campus Araranguá - para facilitar o deslocamento dos alunos e bolsistas nas atividades práticas.

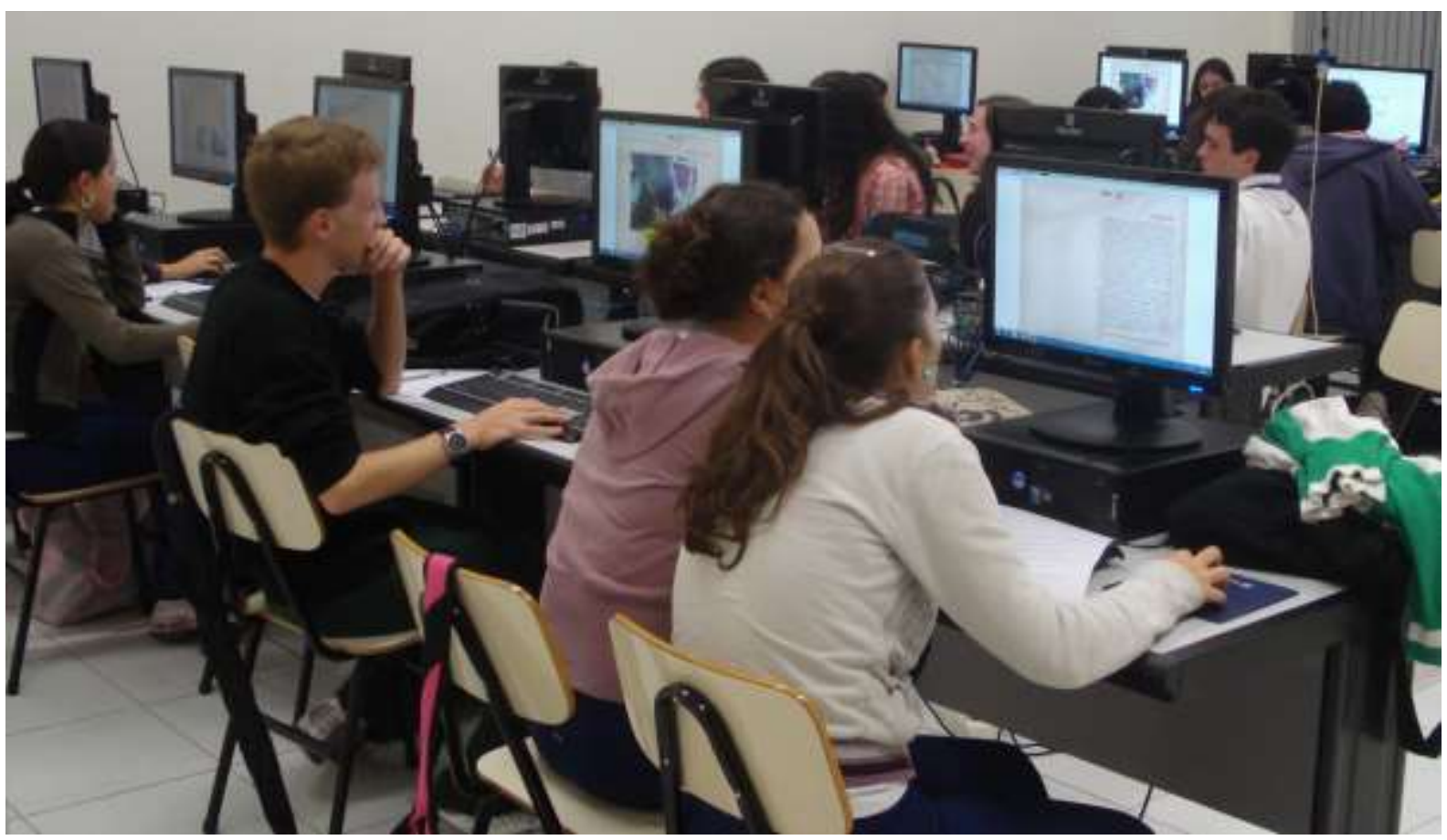

Figura 2: Uso do Ambiente Interativo Virtual AVIFA pelo Grupo 1.

Fonte: Elaborado pelos autores, 2015.

A atuação conjunta dos alunos e pesquisadores de diferentes áreas (multidisciplinar) contribuiu para o fortalecimento profissional dos alunos, em que se pretende que envolvidos tenham também atividades para a sistematização e divulgação dos conhecimentos gerados.

Para o desenvolvimento deste projeto, contou-se com a infraestrutura dos laboratórios da Universidade UFSC com seus equipamentos e computadores, que foram utilizados para os estudos direcionados. Além do mais, vários materiais bibliográficos podem ser encontrados na Internet, bem como a biblioteca da Universidade que possuem livros e periódicos englobando a área em questão, que reforçam as bases teóricas da equipe.

No desenvolvimento do protótipo foi utilizado o ciclo de vida de Engenharia de Software de Summerville (2011), onde o processo de software no modelo espiral é representado na forma de uma espiral em que as sequências de atividades se repetem algumas vezes.

Um ciclo da espiral começa com a elaboração de objetivos, como desempenho e funcionalidade. Os caminhos alternativos para alcançar esses objetivos e as restrições impostas 
sobre cada um deles são, então, enumerados. Cada ciclo na espiral representa uma fase do processo e os setores indicam etapas que o desenvolvimento do sistema pode sofrer, conforme a Figura 3 ilustra.

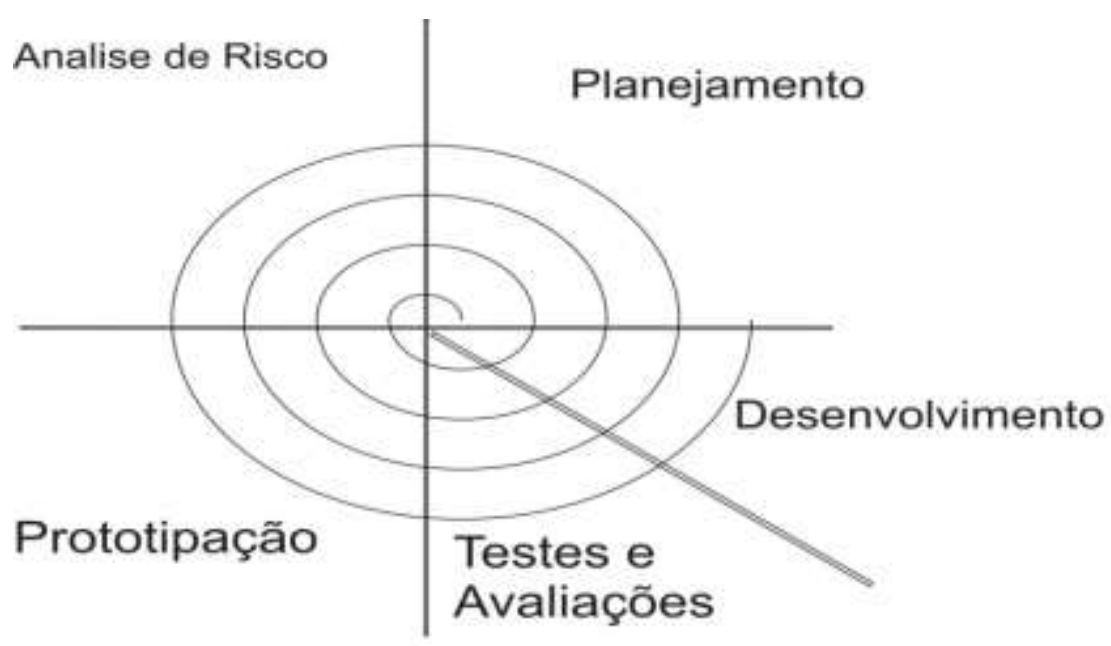

Figura 3: Uso do ciclo de Engenharia de Software Fonte: Adaptado de Summerville, 2011.

Cada alternativa é avaliada em relação a cada objetivo e as fontes de riscos de projeto são identificadas, essas fontes de riscos são na verdade manobra indesejada que a equipe de desenvolvimento deverá fazer para concertar os erros, um exemplo para resolver esses riscos, é por meio de atividades de coleta de informações, tais como analise mais detalhada, prototipação e simulação, evitando a manutenção do sistema.

A etapa de Prototipação é necessária para evitar divergências indesejadas do levantamento de requisito entre cliente e desenvolvedor. Nesta etapa de prototipação é apresentado uma primeira versão do software para o cliente com o objetivo de sanar dúvidas e obter sugestões por parte do cliente e do desenvolvedor.

A equipe dividiu as tarefas para não haver ociosidade de trabalho, distribuindo o desenvolvimento do sistema em grupos responsáveis por tarefas especificas que são posteriormente agrupadas, conforme a técnica de dividir para conquistar. Caracterizando desta maneira como um modelo de Rápido Desenvolvimento de Aplicação - RAD.

Com criação deste modelo híbrido, resultante da união do modelo Espiral e RAD, é possível implementar um ambiente de aprendizagem com diversas equipes de maneira eficiente e ágil. As informações dos clientes são utilizadas pelas diversos grupos responsáveis pela execução das tarefas, conforme a Figura 4. 


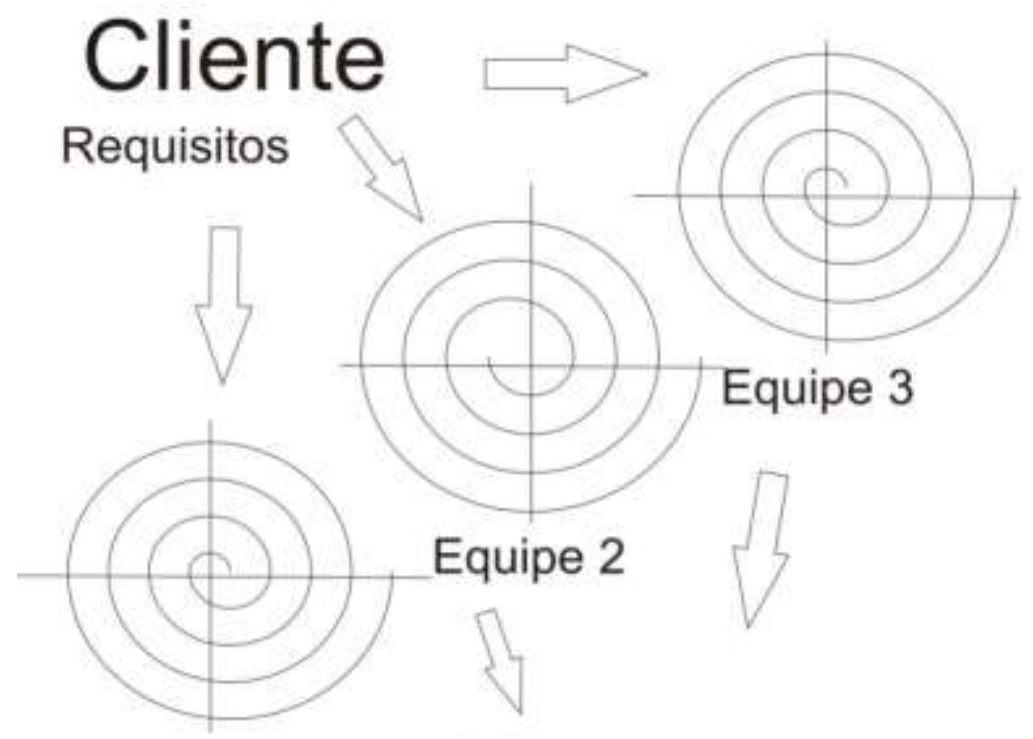

\section{Equipe $1 \longrightarrow$ Sistema}

Figura 4: Modelo Espiral adaptado ao modelo RAD

Fonte: Elaborado pelos autores, 2015.

Cada grupo desenvolve suas tarefas conforme o modelo espiral e os resultados das tarefas executadas são integradas para obter a implementação completa do sistema.

A etapa de testes funcionais, estruturais e verificação são realizadas a cada ciclo para assegurar que a estrutura interna do programa e os requisitos levantados quanto à função do sistema de acordo com o planejado. Além dos testes em cada ciclo, é realizada no ciclo do desenvolvimento a validação do sistema para assegurar que o programa atenda as expectativas do usuário. E posteriormente é realizado o desenvolvimento do sistema.

No contexto técnico, o resultado deste projeto proveu uma base aos alunos bolsistas do curso de Tecnologias da Informação e Comunicação da Universidade UFSC e de Engenharia da Computação da UNIVASF para construir sistemas de ensino-aprendizagem com animações hipermídia. Os resultados deste projeto foram compartilhados com a comunidade científicoacadêmica por meio da divulgação na Semana de Pesquisa e Extensão da Universidade.

\section{RESULTADOS E ANÁLISES}

Foi aplicado o uso do Software com dois grupos, ambos do Ensino Médio da Escola Básica Maria Garcia Pessi de Araranguá, Santa Catarina. A seleção da amostra dos alunos para a 
avaliação do protótipo foi aleatória. Os alunos selecionados participaram das aulas experimentais no ambiente virtual num intervalo de dois meses.

Nas avaliações o grupo-teste foi de 24 alunos (Grupo 1) e 20 (Grupo 2), eles tiveram uma aula de aproximadamente uma hora em que puderam mexer livremente no ambiente com acompanhamento dos bolsistas do projeto e ao fim responderam à um questionário.

Quando perguntados sobre se o conteúdo foi exibido de forma clara, 71\% alunos do Grupo 1 (G1), respondeu que sim, 17\% responderam às vezes e $12 \%$ quase sempre. Não houve negativas(veja Figura 5).

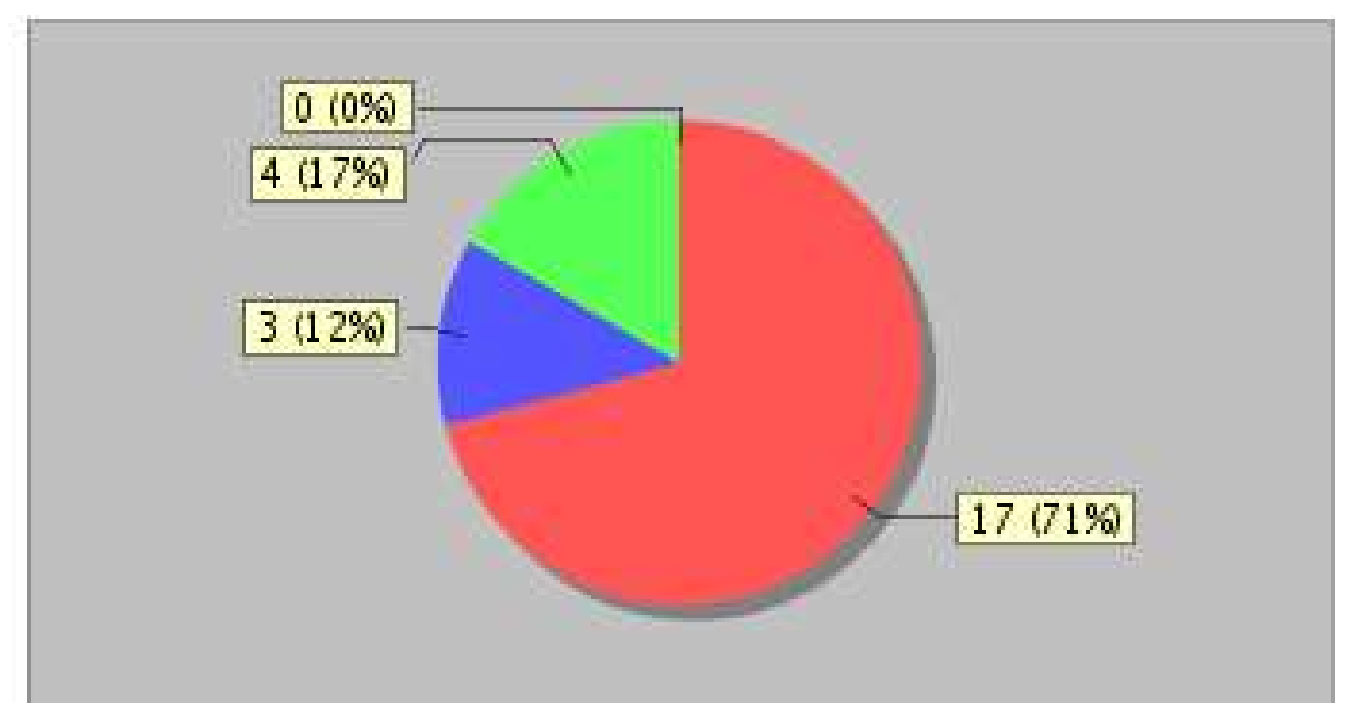

Figura 5. Questão sobre se o conteúdo ser exibido de forma clara.

Fonte: Elaborado pelos autores, 2015.

O objetivo desta questão foi verificar se o conteúdo estava adequado conforme a expectativa do participante do projeto. Alguns comentários foram registrados que o conteúdo estava muito bem distribuído e apresentado nas diferentes mídias utilizadas no ambiente virtual. Vários participantes aprovaram a ideia de incluir vídeos e animações que complementam a escrita. No ambiente o conteúdo abordado foi inserido com explanações, exemplos e animações simulando um exercício prático.

Quando perguntados o ambiente virtual era atrativo (Figura 6), 83\% dos participantes acharam que o método era válido e $17 \%$ dos participantes acharam que não era válido. Os estudantes que responderam que não era válido não explicitaram a sua resposta. 


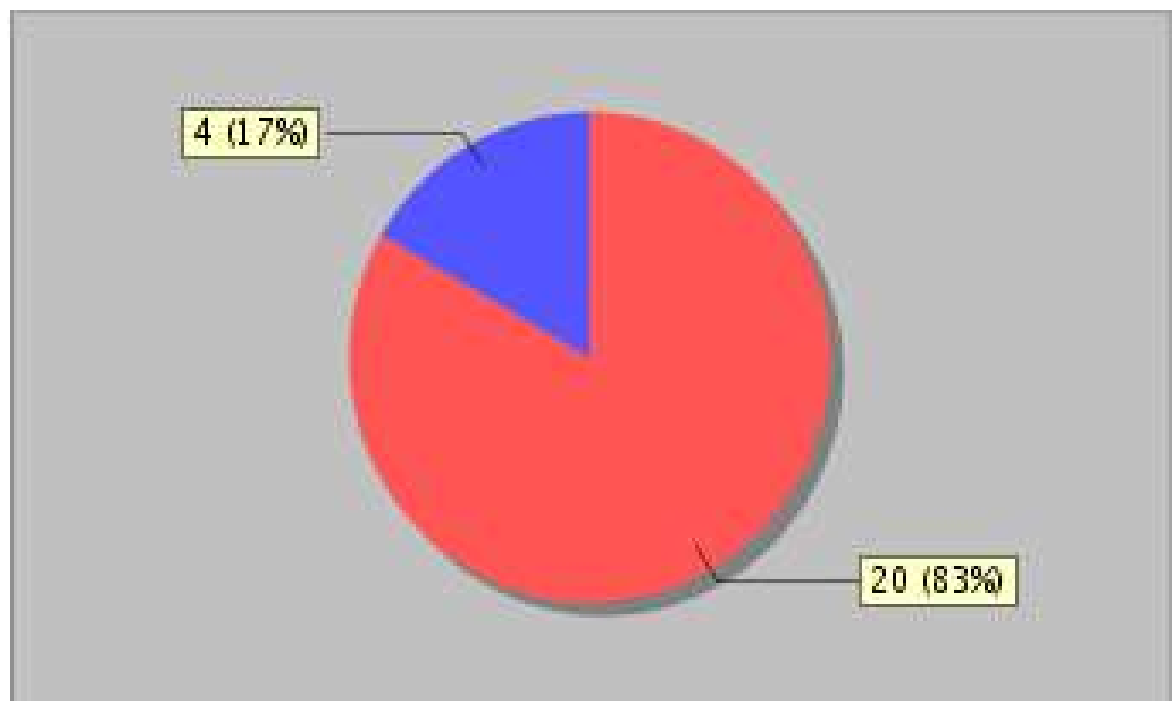

Figura 6. O método de ensino/aprendizagem era atrativo? Fonte: Elaborado pelos autores, 2015.

Resultado igual foi obtido quando perguntados se o computador era o método mais adequado para esse tipo de ensino. $\mathrm{Na}$ Figura 7, é possível observar que nesta questão 83\% responderam que o método era o mais adequado para esse tipo de ensino e $17 \%$ responderam que não.

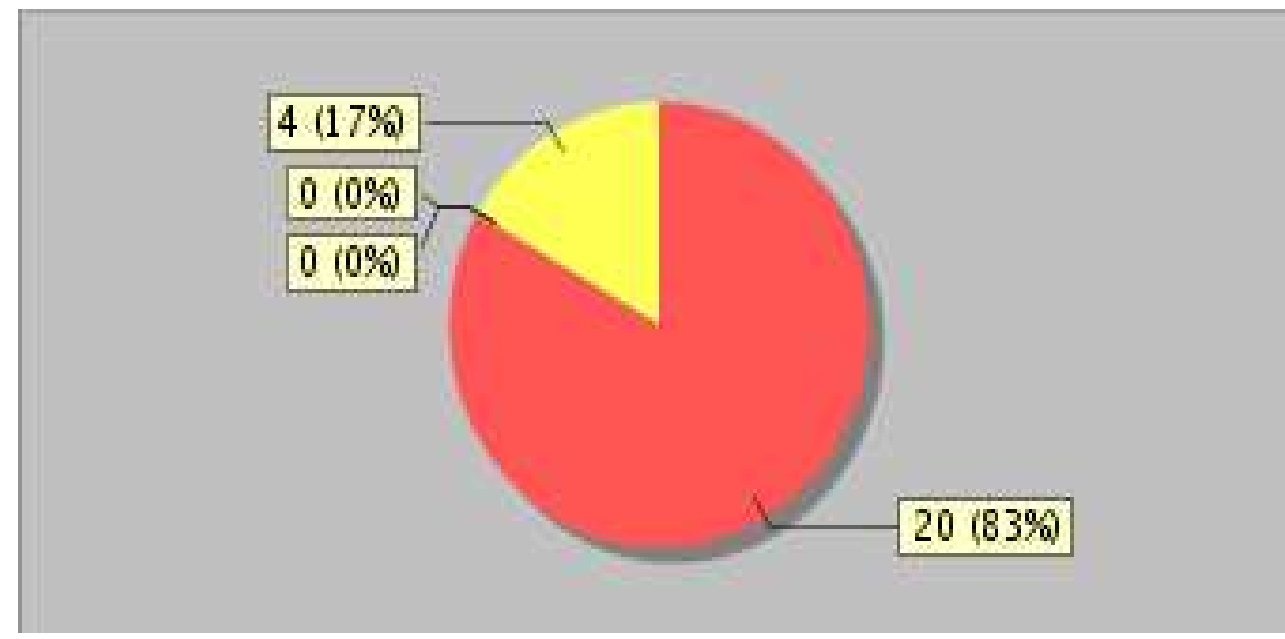

Figura 7. O computador é um método adequado de ensino. Fonte: Elaborado pelos autores, 2015.

Um dos alunos fez a seguinte consideração "É um ótimo projeto e vai melhorar o ensino de muitos, os alunos vão passar a prestar mais atenção". Outros comentaram sobre o tamanho da letra que poderia ser aumentado, o que foi posteriormente corrigido e já apresentado melhorado ao Grupo 2. 
Ambiente virtual para ensino e aprendizagem de fisiologia animal

Existem outros Ambientes Virtuais de Aprendizagem divulgados na comunidade científica, tais como o ambiente para ensino de neurofisiologia (VEDANA, 2002) que é utilizado no ensino e aprendizagem de conteúdos específicos e experiências interativas reais utilizando a internet ligada a um equipamento de um laboratório real (MAROZAS; JURKONIS; LUKOŠEVIČIUS, 2015). Cunhado pelos laboratórios remotos, o termo Experimentação Remota, tem por objetivo criar um apoio pedagógico para o professor utilizar redes globais de laboratórios remotos em ambientes virtuais visando acessar experimentos de forma distribuída (KRBEČEK; SCHAUER, 2015).

\section{CONSIDERAÇÕES FINAIS}

O desenvolvimento do protótipo do ambiente de ensino-aprendizagem para a aprendizagem de fisiologia animal atingiu o objetivo de simular com animações hipermídia os conteúdos referentes às aulas práticas e teóricas, contribuiu para diminuir a utilização de animais experimentais nas práticas de fisiologia ao mesmo tempo em que propiciou a fundamentação dos conteúdos teóricos e práticos ministrados.

Aulas práticas, essenciais para o ensino de fisiologia, têm sido progressivamente diminuídas. Os déficits no aprendizado da Fisiologia animal, provocados pela ausência de aulas práticas com animais, são evidentes, mas podem ser amenizados pela utilização de materiais didáticos informatizados, como a simulação computadorizada de processos fisiológicos que podem substituir a utilização, muitas vezes desnecessária, de animais. Além disso, com o apoio dessa ferramenta didática interações fisiológicas que dificilmente poderiam ser observadas in vivo podem ser demonstradas com maior facilidade em softwares de simulações e utilizadas nas aulas práticas e teóricas, auxiliando na fixação dos conteúdos abordados.

A atuação conjunta dos pesquisadores de diferentes áreas agregou conhecimentos para os alunos envolvidos contribuindo assim para o fortalecimento profissional dos mesmos. Este projeto iniciou-se na Universidade Federal do Vale do São Francisco com integração dos cursos de veterinária e engenharia da computação e depois continuou o seu desenvolvimento na Universidade Federal de Santa Catarina com alunos do curso de bacharel em Tecnologias da Informação e Comunicação. A experiência compartilhada neste projeto entre os alunos e professores das Instituições de Ensino Superior foi interessante para todos os participantes porque aprenderam a trabalhar em equipe e conheceram as tecnologias para modelagem e desenvolvimento do ambiente virtual de ensino e aprendizagem. 
Ambiente virtual para ensino e aprendizagem de fisiologia animal

Como possíveis trabalhos futuros, podem-se agregar ao ambiente virtual diversas estratégias pedagógicas, adaptação do ambiente virtual conforme a preferência do aprendizado do aluno, padronizar a biblioteca de objetos de aprendizagem, incluir várias formas de avaliação dos estudantes e permitir a aprendizagem colaborativa.

\section{AGRADECIMENTOS}

Os autores deste artigo agradecem ao programa PROBOLSA da UFSC pelo auxílio financeiro e apoio da equipe do Laboratório de Tecnologias Computacionais (LabTeC), campus Araranguá-SC.

\section{REFERÊNCIAS}

ALMEIDA, C.W.D.; BRASIL, L. M.; FARIAS, R. A.; BATISTA, L. V.; ALMEIDA, A. E. M.; FERNEDA, E.; COSTA, E. B.; COELHO, V. V.; LAMAS, J. M. Virtual Web System for Realization of Consultation and Diagnosis. In: Proceedings of the Conference on Medical Cybernetics in Clinical Practice in Burdenko Main Military Clinical Hospital, vol. 2. Moscow, Russia, pp.98-110, 2004.

MAROZAS, V.; JURKONIS, R.; LUKOŠEVIČIUS, A. Development of Virtual and Remote Lab Experimentation System for Electronics Engineering. Elektronika ir Elektrotechnika, v. 87, n. 7, p. 41-44, 2015.

KEMCZINSKI, A. Método de Avaliação para Ambientes E-Learning. Tese Doutorado em Engenharia da Produção da UFSC - Universidade Federal de Santa Catarina, Florianópolis-SC, 205 p., 2005.

KRBEČEK, M.; SCHAUER, F. Communication and Diagnostic Interfaces in Remote Laboratory Management Systems. International Journal of Online Engineering (iJOE), v. 11, n. 5, 2015.

ROEHRS, P. D.; MULLER, L.; ARRUDA, A. P. Novos ambientes educacionais: desafios do uso das tecnologias educacionais inovadoras no context escolar. Revista Eletrônica em Gestão, Educação e Tecnologia Digital, v.18, n.1, 2014.

SOMMERVILLE, I. Engenharia de software, $9^{\circ}$ ed., São Paulo : Pearson Prentice Hall, São Paulo, 2011. 
Ambiente virtual para ensino e aprendizagem de fisiologia animal

VEDANA, S. B. ; POZZEBON, E, ; ALMEIDA, M. A. F. ; BARRETO, J. M. Ambiente Computacional para Ensino de Neurofisiologia. Anais do XXII Encontro Nacional de Engenharia de Produção, p.101-108, 2002. 